\title{
BMJ Open Investigating the long-term impact of a childhood sun-exposure intervention, with a focus on eye health: protocol for the Kidskin-Young Adult Myopia Study
}

\author{
Gareth Lingham, ${ }^{1}$ Elizabeth Milne, ${ }^{2}$ Donna Cross, ${ }^{2}$ Dallas R English, ${ }^{3}$ \\ Robyn S Johnston, ${ }^{4}$ Robyn M Lucas, ${ }^{1,5}$ Seyhan Yazar, ${ }^{1}$ David A Mackey ${ }^{1}$
}

To cite: Lingham G, Milne E, Cross D, et al. Investigating the long-term impact of a childhood sun-exposure intervention, with a focus on eye health: protocol for the Kidskin-Young Adult Myopia Study. BMJ Open 2018;8:e020868. doi:10.1136/ bmjopen-2017-020868

- Prepublication history for this paper is available online. To view these files, please visit the journal online (http://dx.doi. org/10.1136/bmjopen-2017020868).

Received 28 November 2017 Accepted 1 December 2017

Check for updates

${ }^{1}$ Centre for Ophthalmology and Visual Science, Lions Eye Institute, University of Western Australia, Nedlands, Western

Australia, Australia

${ }^{2}$ Telethon Kids Institute, University of Western Australia, West Perth, Western Australia, Australia

${ }^{3}$ Centre for Epidemiology and Biostatistics, University of Melbourne, Melbourne, Victoria, Australia

${ }^{4}$ McCusker Centre for Action on Alcohol and Youth, Curtin University, Bentley, Western Australia, Australia

${ }^{5}$ National Centre for Epidemiology and Population Health, Australian National University, Canberra, Australian Capital Territory, Australia

Correspondence to

Prof. David A Mackey;

davidmackey@lei.org.au

\section{ABSTRACT}

Introduction Excessive and insufficient sun exposure during childhood have been linked to serious diseases in later life; for example, insufficient sun exposure during childhood may increase the risk of developing myopia. The Kidskin-Young Adult Myopia Study (K-YAMS) is a follow-up of participants in the Kidskin Study, a non-randomised controlled trial that evaluated the effect of a 4-year educational intervention on sun-protection behaviours among primary school children in the late 1990s. Children who received the Kidskin intervention had lower levels of sun exposure compared with peers in the control group after 2 and 4 years of the intervention, but this was not maintained 2 years after the intervention had ceased. Thus, a follow-up of Kidskin Study participants provides a novel opportunity to investigate the associations between a childhood sun-exposure intervention and potentially related conditions in adulthood.

Methods and analysis The K-YAMS contacts Kidskin Study participants and invites them to participate using a variety of methods, such as prior contact details, the Australian Electoral Roll and social media. Self-reported and objective measures of sun-exposure and sunprotection behaviours are collected as well as a number of eye measurements including cycloplegic autorefraction and ocular biometry. Data will be analysed to investigate a possible association between myopic refractive error and Kidskin intervention group or measured sun exposure. Ethics and dissemination The K-YAMS is approved by the Human Research Ethics Committee of the University of Western Australia (RA/4/1/6807). Findings will be disseminated via scientific journals and conferences. Trial registration number ACTRN12616000812392; Preresults.

\section{INTRODUCTION}

High levels of sun exposure during childhood increase the risk of melanoma in later life. ${ }^{1}$ However, a lack of sun exposure during childhood has been linked to the development of diseases such as myopia, ${ }^{2} 3$ multiple sclerosis $^{4}$ and type 1 diabetes mellitus. ${ }^{5}$ Myopia (near-sightedness) is a common condition affecting approximately $24 \%$ of

\section{Strengths and limitations of this study}

- The Kidskin-Young Adult Myopia Study participants were involved in a well-conducted and welldescribed interventional trial which successfully reduced sun exposure for a defined period of childhood.

- Multiple objective and subjective measures of recent and cumulative sun exposure are collected.

- Participants undergo a comprehensive eye examination with measurement of multiple ocular parameters.

- Most Kidskin participants have not been contacted for 16 years, therefore, recruitment may be challenging; however, multiple recruitment strategies are planned to re-engage participants.

20-year olds in Australia. ${ }^{6}$ The prevalence of myopia is increasing in many parts of the world, and current research aims to prevent the onset or progression of myopia and the potentially blinding diseases associated with myopia. ${ }^{6-8}$ Recent randomised clinical trials in Chinese school children have shown that spending extra time outside during the day prevented the onset of myopia in some children $^{29}$; however, it is unknown whether sun exposure, increased retinal illumination or viewing of distant objects is responsible for this beneficial effect.

Between 1995 and 2001, Western Australian researchers conducted the Kidskin Study, a 6-year non-randomised controlled trial that aimed to 'design, implement and evaluate an intervention to reduce sun exposure in children $^{10}$ and thus reduce the risk of melanoma in later life. ${ }^{1011}$ Eligible participants were those attending their first year of schooling in 1995 at a participating school, all of which were located within $30 \mathrm{~km}$ of Perth. Of the 2528 children invited to participate in the Kidskin Study, consent was provided by a parent or 


\begin{tabular}{|c|c|c|c|c|c|c|c|}
\hline & 1995 & 1996 & 1997 & 1998 & 1999 & 2000 & 2001 \\
\hline Intervention & Spring* & Spring & Spring & Spring & & & \\
\hline Suntan† & & & Summer $\ddagger^{*}$ & & Summerł & & Summerł \\
\hline Questionnaire & Spring & & Summerł & & Summerł & & Summerł \\
\hline Constitutional†§ & Winter ${ }^{*}$ & & & & Winter & & Winter \\
\hline Naevus counts & Winter & & & & Winter & & Winter \\
\hline
\end{tabular}

Adapted from Milne. ${ }^{11}$

*In Australia, summer is from December to February, autumn from March to May, winter from June to August and spring from September to November.

†Measured by skin spectrophotometry.

$\ddagger$ Measured at the end of summer immediately after school holidays.

$\S$ Constitutional skin colour measured from inner arm.

legal guardian for 1776 participants. ${ }^{10}$ Table 1 provides an overview of the schedule of the intervention and outcome measurements in the Kidskin Study. ${ }^{11}{ }^{12}$ During the intervention period between the spring of 1995 and the summer of 1998-1999, participants were assigned to a high-intervention, a moderate-intervention or a no-intervention comparison group (hereafter referred to as high, moderate or control groups) and were examined at ages 5-6 (baseline), 7-8, 9-10 (end of intervention) and 11-12 years. ${ }^{1012} 13$ The intervention was a specially designed curriculum that was administered to the high and moderate groups and replaced the regular sun safety education curriculum. The Kidskin Study curriculum was designed to be developmentally appropriate and skills-based and included both school-based and homebased activities that were administered in school by the children's primary school teacher. ${ }^{13}$ In addition to the Kidskin Study curriculum, the high group also received 'Totally Cool Summer Club' programme material over the summer holidays and was offered low-cost swimwear that protected the trunk, upper arms and thighs. Schools allocated to the high-intervention group were also given assistance in implementing sun-protection policies. ${ }^{10}$ The control group received the standard Western Australian health education curriculum over the same period. ${ }^{10}$

The primary outcome was change in number of melanocytic naevi on the back at the 4-year follow-up. This was not significantly different between the high, moderate and control groups at the end of intervention (1999) and 2-year postintervention (2001) follow-ups. Analysis of secondary outcomes showed that parents of children in the high group reported that their child experienced less whole body sun exposure than that reported by the parents in the control group at the 2-year and 4-year follow-ups (1997 and 1999). ${ }^{11}{ }^{14}$ Parents of children in both intervention groups reported that their children spent less time outside between 11:00 and 14:00 at the 2-year follow-up, but at the 4-year follow-up, only children in the high group had significantly lower reported time spent outdoors between 11:00 and 14:00 compared with the control group. ${ }^{12}{ }^{14}$ Measurement of suntan using skin spectrophotometry showed that children in the high and moderate groups had a significantly lower level of suntan at the end of summer than the control group at the 2-year follow-up. ${ }^{15}$ However, there was no significant difference at the 4-year and postintervention follow-ups. ${ }^{12}$ The skin spectrophotometer had to be changed between the 2-year and 4-year follow-ups as it became unserviceable, and this change in measurement instrument may be a factor in the lack of an association between measured suntan and intervention group at the later follow-ups. ${ }^{12}$ At the final Kidskin Study follow-up in 2001, 2years after the intervention had ceased, there was no significant difference in suntan or sun exposure between children in the high, moderate and control groups with the exception of applying sunscreen to the back, which was more common in the moderate and high groups.

The size, quality and length of intervention and follow-up of the Kidskin Study make it unique among studies of child and adolescent sun protection. Other sun-protection intervention studies have had mixed results in reducing sun exposure in participants. Studies finding no effect of an intervention, lacking a control group or not longitudinally following the same participants have limited usefulness when investigating the impacts of sun exposure during childhood. ${ }^{16-20}$ Of the studies that have successfully reduced sun exposure in the intervention group compared with the control group, all have had shorter intervention and follow-up periods than the Kidskin Study. ${ }^{21-23}$

Hence, the Kidskin Study provides a novel opportunity to investigate the association between sun exposure during childhood and the development of potentially related conditions in adulthood. The intervention study formed a cohort in which particular groups of participants had different levels of sun exposure during a well-defined period in primary school. Additionally, participants had both subjective and objective measurements of sun exposure recorded at multiple time points throughout childhood.

The Kidskin Study participants are 27-28 years old in 2017-an age when the prevalence of myopia, a disorder that predominantly develops in younger life-has generally stabilised. ${ }^{24}$ The Kidskin Young Adult Myopia Study 
(K-YAMS) will follow-up participants in the Kidskin Study, to determine the long-term effects on health - particularly eye health-of a sun-protection intervention during childhood.

\section{METHODS AND ANALYSIS \\ Recruitment}

The K-YAMS aims to use the established Kidskin Study cohort to investigate the association between the Kidskin intervention and the prevalence of myopia in participants of the Kidskin Study, who are now young adults. Recruitment for the K-YAMS began in May 2015 and will be completed by the end of 2018. All participants of the Kidskin Study are eligible to participate. The expected follow-up sample size $(\mathrm{n} \sim 800)$ is likely to be too small to investigate rarer outcomes such as type 1 diabetes mellitus, but will be large enough to detect differences in relatively common disorders such as myopia.

While a significant amount of time has passed since the Kidskin participants were last contacted, approximately one-third $(n=547)$ of participants responded to a mail out invitation to provide a saliva sample in 2005 ; however, since 2001, the majority of the Kidskin participants have not been contacted. We are therefore using a variety of approaches to contact participants including previous address and telephone or mobile phone details from the Kidskin Study, Facebook, the Australian Electoral Roll and snowball recruiting from participants we have been able to contact, asking them to help spread awareness of the K-YAMS to their schoolmates.

\section{Data collection}

An overview of the measures being collected in the K-YAMS is given in table 2. The K-YAMS focuses on

\begin{tabular}{|c|c|c|}
\hline $\begin{array}{l}\text { Eye and vision } \\
\text { measures }\end{array}$ & $\begin{array}{l}\text { Sun-exposure } \\
\text { measures }\end{array}$ & $\begin{array}{l}\text { Other health } \\
\text { measures }\end{array}$ \\
\hline $\begin{array}{l}\text { Refractive error } \\
\text { Strength of current } \\
\text { prescribed glasses } \\
\text { Visual acuity } \\
\text { Corneal endothelial cell } \\
\text { count } \\
\text { Ocular motility and } \\
\text { stereoacuity status } \\
\text { Eye colour photography } \\
\text { Ocular biometry } \\
\text { Intraocular pressure } \\
\text { Macular and optic disc } \\
\text { parameters measured } \\
\text { using HRT and OCT } \\
\text { Retinal photography }\end{array}$ & $\begin{array}{l}\text { Sun damage } \\
\text { measured from } \\
\text { silicone skin cast } \\
\text { of back of right } \\
\text { hand } \\
\text { Serum 25(OH)D } \\
\text { concentration } \\
\text { Ocular sun } \\
\text { exposure } \\
\text { (CUVAF) } \\
\text { Self-reported } \\
\text { history of sun } \\
\text { exposure }\end{array}$ & $\begin{array}{l}\text { Height } \\
\text { Weight } \\
\text { Blood } \\
\text { pressure } \\
\text { Naevi count } \\
\text { on back } \\
\text { Naevi count } \\
\text { on right arm } \\
\text { DNA } \\
\text { Self-reported } \\
\text { skin and hair } \\
\text { phenotypes }\end{array}$ \\
\hline
\end{tabular}

25(OH)D, 25-hydroxy vitamin D; CUVAF, conjunctival ultraviolet autofluorescence; HRT, Heidelberg retina tomography; K-YAMS, Kidskin-Young Adult Myopia Study; OCT, optical coherence tomography. myopia and eye health; however, a number of other broader health measures are also being collected. Participants are required to attend a study examination at the Lions Eye Institute in Perth, Western Australia. Written informed consent is obtained from all participants prior to the study examination.

\section{Self-reported data}

Participants are asked to complete a questionnaire as well as a sun calendar at home or during the study visit. Questionnaire data include current demographics, medical and ophthalmic history, recent and past sun exposure, natural hair colour, skin type and skin reaction after sun exposure. The sun calendar asks participants to report city of residence and sun-exposure (summer and winter in categories of 'less than half an hour per day', 'half to 1 hour', '1-2 hours', '2-3 hours', ' $3-4$ hours' and 'more than 4hours') and sun-protection behaviours (hat, sunglasses and sunscreen in categories of 'never', 'less than half of the time', 'half of the time', 'more than half of the time' and 'all of the time') for each year of life from 5 years of age onward. The self-reported calendar data for the period of the intervention will be compared with the self-reported and measured data on sun exposure and sun protection for the intervention period.

\section{Exposure measurements}

A variety of objective measures of sun exposure are being collected to gain a better understanding of each individual's past and recent exposure to sun. Skin photodamage is measured using silicone skin casts taken from the back of participants' right hands and graded on a scale of 1 to 6 , as previously described by Holman et $a l,{ }^{25}$ where grade 1 represents no or little sun-related skin damage and grade 6 represents severe skin damage. ${ }^{25} 26$ Participants will have their back photographed and the number of naevi counted by a trained examiner. ${ }^{27}$ Conjunctival ultraviolet autofluorescence photographs to measure past sun exposure of the eye are captured using a Nikon D100 camera (Nikon, Melville, New York, USA) with a B+W 486 UV IR filter (Schneider Kreuznach, Bad Kreuznach, Rhineland-Palatinate, Germany) fitted to a $105 \mathrm{~mm}$ f/2.8 Micro Nikkor lens (Nikon). Two Metz 36 C-2 flashes (Metz, Zirndorf, Middle Franconia, Germany) with 18A Wratten glass filters fitted over the flash heads are used as the excitation source. Blood is taken by venepuncture into serum separator tubes. One millilitre aliquots of serum are frozen at $-40^{\circ} \mathrm{C}$ until the completion of the study. Liquid chromatography tandem-mass spectrometry will then be used to measure serum 25-hydroxy vitamin D concentration, as a marker of recent sun exposure, after completion of data collection.

\section{Outcome measurements}

Participants have refractive error measurements taken using cycloplegic autorefraction (Nidek ARK-510A; Nidek, Japan). Myopia is defined as a spherical 
equivalent $\leq 0.50$ dioptres (D) (calculated as sphere $+1 / 2$ cylinder). A variety of other eye and vision measurements are collected including visual acuity (ETDRS chart R; Precision Vision, Woodstock, Illinois, USA), ocular biometry (IOL master 500; Carl Zeiss Meditec, Jena, Germany), intraocular pressure (icare TA01i; icare, Vantaa, Finland), optical coherence tomography (Spectralis HRA+OCT; Heidelberg Engineering, Heidelberg, Germany) and fundus photography (CF-60DSi; Canon, USA).

\section{Data analysis}

The primary analysis of the K-YAMS will test the association between spherical equivalent/prevalence of myopia and intervention group of the Kidskin Study. Linear and logistic regression models will be constructed to investigate the impacts of the Kidskin Study intervention on continuous and categorical outcomes, respectively, while adjusting for covariates such as age and education. Secondary analysis will involve the construction of further linear and logistic regression models to investigate the associations between past sun exposure, irrespective of Kidskin Study intervention arm, and ocular parameters such as spherical equivalent and axial length, while adjusting for confounding variables.

We will have $99.63 \%$ power to detect a difference of $0.50 \mathrm{D}$ of spherical equivalent between the high intervention and control groups with a sample size of 800 . However, if we are unable to meet our recruitment target, we will still have $96.7 \%$ and $87.5 \%$ power to detect a difference of $0.50 \mathrm{D}$ between the high and control groups with sample sizes of 600 and 400, respectively.

\section{Implications}

Australia has the highest skin cancer incidence in the world; melanoma is the deadliest of the skin cancers and is particularly associated with childhood sun exposure. ${ }^{28}$ Incidence rates of melanoma were rapidly rising in the late 20th century. In the face of this, Australia led the world in developing sun-protection programmes to reduce childhood sun exposure. Encouragingly, the incidence of melanoma in Australia has remained stable since $2006 .^{28}$ However, recent evidence suggests that there may be beneficial effects of sun exposure, such as preventing onset of myopia, and it is now essential to understand these effects to find a balance between excessive and insufficient sun exposure. ${ }^{5} 29$ Unfortunately, the impact of childhood sun exposure is difficult to study. First, the effects-both beneficial and detrimental-can take a long time to manifest so that either recall of distant events is required for retrospective studies or long length of follow-up is required for prospective studies. Second, observational studies of sun exposure are unable to attribute observed associations specifically to sun exposure, due to other confounding factors that often accompany sun exposure, such as physical activity. Randomised controlled trials can overcome this issue, but are difficult and costly to run, and can pose ethical dilemmas, for example, where the full effects of an intervention have potential adverse effects on health. In addition, in an intervention study, it may be a long time before the harmful or beneficial effects of the intervention are fully appreciated. The Kidskin Study was a thorough controlled trial that was completed in 1999 and presents a truly unique opportunity to immediately begin studying the effects of an intervention which successfully reduced sun exposure compared with controls. A difference in myopia prevalence across the intervention groups may suggest that the age period over which Kidskin participants received the intervention is a key period in the development of myopia. This age group could then be targeted by public health campaigns aimed at preventing the onset of myopia in at-risk children through a controlled increase in time spent outside. However, the utility of the Kidskin Study cohort is not limited to myopia, and further follow-ups could provide crucial information in examining the effects of reducing childhood sun exposure.

\section{ETHICS AND DISSEMINATION}

Findings from the K-YAMS will be disseminated via publication in scientific peer-reviewed journals and presentation at national and international conferences. K-YAMS participants will also be notified of publications and provided with a copy where possible. All subjects provide written informed consent prior to participating in the study and are made aware that they may withdraw their consent at any time or refuse any procedure such as venepuncture or administration of cycloplegic eye-drops. A trained medical doctor is present during study examinations in the unlikely event of an adverse event occurring.

Contributors GL, DAM, SY and RML were involved in the conception and design of this manuscript. EM, DRE, DC and RSJ were involved in the conception, design, implementation, data collection and analysis of the Kidskin Study between 1995 and 2001. DAM, SY, RML and EM were involved in the conception and design of the K-YAMS. GL was responsible for the initial drafting of the manuscript. All authors critically reviewed, revised and contributed to the manuscript.

Funding A pilot study of the K-YAMS was funded by a Perpetual Impact Philanthropy Grant (IPAP2015/0230). The K-YAMS study is funded by a competitive, peer-reviewed Project Grant from the National Health and Medical Research Council (1121979). GL receives financial support through an Australia Government Research Training Program Scholarship. SY is supported by a National Health and Medical Research Council CJ Martin Early Career Fellowship. DC is supported by a National Health and Medical Research Council Research Fellowship GNT 1119339. RML is supported by a National Health and Medical Research Council Senior Research Fellowship (\#1107343) and a Cancer Australia grant.

Competing interests None declared.

Patient consent Parental/guardian consent obtained.

Ethics approval K-YAMS is approved by the Human Research Ethics Committee of the University of Western Australia (RA/4/1/6807).

Provenance and peer review Not commissioned; peer reviewed for ethical and funding approval prior to submission.

Open Access This is an Open Access article distributed in accordance with the Creative Commons Attribution Non Commercial (CC BY-NC 4.0) license, which permits others to distribute, remix, adapt, build upon this work non-commercially, and license their derivative works on different terms, provided the original work is 
properly cited and the use is non-commercial. See: http://creativecommons.org/ licenses/by-nc/4.0/

(C) Article author(s) (or their employer(s) unless otherwise stated in the text of the article) 2018. All rights reserved. No commercial use is permitted unless otherwise expressly granted.

\section{REFERENCES}

1. Gandini S, Sera F, Cattaruzza MS, et al. Meta-analysis of risk factors for cutaneous melanoma: II. Sun exposure. Eur J Cancer 2005;41:45-60

2. He M, Xiang F, Zeng $Y$, et al. Effect of time spent outdoors at school on the development of myopia among children in China: a randomized clinical trial. JAMA 2015;314:1142-8.

3. Yazar S, Hewitt AW, Black LJ, et al. Myopia is associated with lower vitamin D status in young adults Myopia and vitamin D status. Invest Ophthalmol \& Vis Sci 2014;55:4552-9.

4. Islam T, Gauderman WJ, Cozen W, et al. Childhood sun exposure influences risk of multiple sclerosis in monozygotic twins. Neurology 2007;69:381-8.

5. Mohr SB, Garland CF, Gorham ED, et al. The association between ultraviolet $B$ irradiance, vitamin D status and incidence rates of type 1 diabetes in 51 regions worldwide. Diabetologia 2008;51:1391-8.

6. McKnight CM, Sherwin JC, Yazar S, et al. Myopia in young adults is inversely related to an objective marker of ocular sun exposure: the Western Australian Raine cohort study. Am J Ophthalmol 2014;158:1079-85.

7. Vongphanit J, Mitchell P, Wang JJ. Prevalence and progression of myopic retinopathy in an older population. Ophthalmology 2002;109:704-11.

8. Mitry D, Charteris DG, Fleck BW, et al. The epidemiology of rhegmatogenous retinal detachment: geographical variation and clinical associations. Br J Ophthalmol 2010;94:678-84.

9. Wu PC, Tsai CL, Wu HL, Pc W, HI W, et al. Outdoor activity during class recess reduces myopia onset and progression in schoo children. Ophthalmology 2013;120:1080-5.

10. Milne E, English DR, Cross D, et al. Evaluation of an intervention to reduce sun exposure in children: design and baseline results. $A m \mathrm{~J}$ Epidemiol 1999;150:164-73.

11. Milne E. The effect of a school-based sun protection intervention on sun-related behaviour and the development of melanocytic naevi in children [PhD]: University of Western Australia, 2001.

12. Milne E, Jacoby P, Giles-Corti B, et al. The impact of the kidskin sun protection intervention on summer suntan and reported sun exposure: was it sustained? Prev Med 2006;42:14-20.

13. Johnston R, Cross $D$, Costa $C$, et al. Sun safety education intervention for school and home. Health Educ 2003;103:342-51.
14. Milne E, English DR, Johnston R, et al. Improved sun protection behaviour in children after two years of the Kidskin intervention. Aust N Z J Public Health 2000;24:481-7.

15. Milne E, English DR, Johnston R, et al. Reduced sun exposure and tanning in children after 2 years of a school-based intervention (Australia). Cancer Causes Control 2001;12:387-93.

16. Crane LA, Schneider LS, Yohn JJ, et al. 'Block the sun, not the fun': evaluation of a skin cancer prevention program for child care centers. Am J Prev Med 1999;17:31-7.

17. Girgis A, Sanson-Fisher RW, Tripodi DA, et al. Evaluation of interventions to improve solar protection in primary schools. Health Educ Q 1993;20:275-87.

18. Miller DR, Geller AC, Wood MC, et al. The falmouth safe skin project: evaluation of a community program to promote sun protection in youth. Health Educ Behav 1999;26:369-84.

19. Dietrich AJ, Olson AL, Sox CH, et al. Persistent increase in children's sun protection in a randomized controlled community trial. Prev Med 2000;31:569-74.

20. Gritz ER, Tripp MK, James AS, et al. An intervention for parents to promote preschool children's sun protection: effects of Sun Protection is Fun!. Prev Med 2005:41:357-66.

21. Buller DB, Reynolds KD, Yaroch A, et al. Effects of the sunny days, healthy ways curriculum on students in grades 6 to 8 . Am J Prev Med 2006;30:13-22.

22. Buller DB, Taylor AM, Buller MK, et al. Evaluation of the sunny days, healthy ways sun safety curriculum for children in kindergarten through fifth grade. Pediatr Dermatol 2006;23:321-9.

23. Gallagher RP, Rivers JK, Lee TK, et al. Broad-spectrum sunscreen use and the development of new nevi in white children: A randomized controlled trial. JAMA 2000;283:2955-60.

24. Goldblum D, Brugger A, Haselhoff A, et al. Longitudinal change of refraction over at least 5 years in 15,000 patients. Graefes Arch Clin Exp Ophthalmol 2013;251:1431-6.

25. Holman CD, Armstrong BK, Evans PR, et al. Relationship of solar keratosis and history of skin cancer to objective measures of actinic skin damage. Br J Dermatol 1984;110:129-38.

26. Lucas RM, Ponsonby AL, Dear K, et al. Associations between silicone skin cast score, cumulative sun exposure, and other factors in the ausimmune study: a multicenter Australian study. Cancer Epidemiol Biomarkers Prev 2009;18:2887-94.

27. English DR, Milne E, Jacoby P, et al. The effect of a school-based sun protection intervention on the development of melanocytic nevi in children: 6-year follow-up. Cancer Epidemiol Biomarkers Prev 2005;14:977-80.

28. Australian Institute of Health and Welfare. Skin cancer in Australia. 2016. http://www.aihw.gov.au/WorkArea/DownloadAsset.aspx?id= 60129556026 (accessed 19 Jan 2017)

29. Lucas RM, Ponsonby AL, Dear K, et al. Sun exposure and vitamin $\mathrm{D}$ are independent risk factors for CNS demyelination. Neurology 2011;76:540-8. 